Proceedings

\title{
Interrelationship between Environmental Drivers and Avian Biodiversity in a Mediterranean Like Natura 2000 Wetland and Implications for Conservation Management ${ }^{+}$
}

\author{
Polyxeni Soulopoulou ${ }^{1, *}$, Juan Antonio Marco Molina ${ }^{2}$, Maria Ascension Padilla Blanco ${ }^{2}$ and Petros Damos $^{3}$ \\ 1 Department of Biodiversity and Conservation, University of Alicante, Spain; polyxenisoulopoulou@ya- \\ hoo.gr, ps62@alu.ua.es \\ 2 University Institute for Biodiversity (CIBIO), University of Alicante, Spain; ja.marco@ua.es, ma.pa- \\ dilla@ua.es \\ 3 AHEPA University General Hospital of Thessaloniki, Aristotle University of Thessaloniki (AUTh), Greece; \\ petrosdamos@gmail.com \\ Correspondence: polyxenisoulopoulou@yahoo.gr, ps62@alu.ua.es
}

Citation: Lastname, F.; Lastname, F.; Lastname, F. Title. Proceedings 2021, 68, x. https://doi.org/10.3390/xxxxx

Published: date

Publisher's Note: MDPI stays neutral with regard to jurisdictional claims in published maps and institutional affiliations.

Copyright: (c) 2021 by the authors. Submitted for possible open access publication under the terms and conditions of the Creative Commons Attribution (CC BY) license (http://creativecommons.org/licenses /by/4.0/).
Abstract: In this work we address the question of how certain climatic variables may be significant related to alterations of avian biodiversity in a semi-agricultural Natura wetland side in Northern Greece. In particular, we examine the interplay between temperature, relative humidity and three different bird biodiversity indexes, including Shannon Entropy, Simpson's dominance (evenness) index and the Berger-Parker index. By using different modeling approaches, parametric and nonparametric multivariate models, we make effort to get a consensus on the interrelationships between climate and avian biodiversity. In particular, we show that in most cases nonlinear models and surface-plot analysis methodology, are able to capture the relation of a considerable increase in the estimated biodiversity indexes with increased temperatures and rain levels. Thus, biodiversity is to a significant extent affected by the aforementioned climate factors at a proximate level involving synergies between the different climate factors. Revealing potential interrelationship between biodiversity and climate drivers although is a complex - even though challenging - task, contributing to our understanding of the mechanisms connecting climate change with ecosystem functioning. Moreover, a better understanding of biodiversity functioning in relation to climate is essential for biodiversity awareness and the design of effective biodiversity-related conservation management policies.

Keywords: climate; biodiversity modeling; semi-agricultural landscape; Shannon Entropy

\section{Introduction}

Greece is distinguished for its great biological diversity, which is one of Largest in Europe and the Mediterranean [1]. The biodiversity of Greece is very rich due to its geographical placement, consisting of from European, Asian, African and many endemic species including more than 5,500 species of higher plants, 436 species of birds, 116 species of mammals, 79 species of reptiles and amphibians, 110 species of freshwater fish, 447 species of sea fish and about 4000 species invertebrates [2]. Moreover, Greece's biodiversity consists of many endemic species which have a very limited spread (e.g., on a single island or areas) and are therefore very sensitive to disturbances.

Climate change is increasingly being recognized as a serious threat, especially in what concerns coastal, alpine and arctic species and habitats $[3,4]$. According to the European Commission Green Paper (2007), most Vulnerable areas of Europe are the following: Southern Europe and the whole of the Mediterranean basin due, on the one hand, to high temperature and on the other hand, the decrease of rainfall in areas where water scarcity 
is already observed. It is pointed out that southern Europe is already experiencing extremely dry weather, with rainfall to have increased by up to $20 \%$ during the 20th century.

Seasonal and year to year alterations of climate factors, including temperatures and rain events, may have direct and indirect effects on species biodiversity. The effects of climate in bird biodiversity are multifaceted including [2-5]: (i) direct effects on species bio-demography (e.g., affecting survival, reproductive success rates and population dynamics, (ii) effects through biotic interactions (e.g., concession of competitive advantage, niche occupation and dispersion) (iii) effects through habitat changes (e.g., flooding in water, dry weather conditions and related landscape modifications).

Furthermore, climate alterations affect ecosystem structure and biodiversity in a combined way causing alterations in river arrangements, water abstractions and land use [6,7]. Any significant reduction of wetlands, due to an increase in temperature for instance, is expected to affect the routes of migratory birds, which depend mainly on availability of suitable Mediterranean habitats for wintering and rest during their course from north to south. Despite the importance of environmental drivers in species biodiversity, there are few studies which focus on the relationship between species biodiversity and climate conditions [8]. Moreover, although some studies performed on species level in local scale (e.g., [9]), there are no specific studies which study the effect of climate factors in bird biodiversity in Northern Greece.

There are 182 species of animals of Community interest in Greece, in accordance with the Directive 92/43 / EEC and according to the results of the 2nd national report on the implementation of the Directive 92/43 / EEC for the period 2000 - 2006 [10], there are major deficiencies in terms of spatial planning, range and population of these species. Therefore, there is an ongoing interest to detect any changes in avian biodiversity and how they are affected by different environmental drivers.

In previous works we have detected alterations in avian biodiversity throughout the last years in a representative Natura 2000 wetland in Northern Greece [11]. The objective of the current work is the detection of the existence of interrelationships between some of the most important environmental drivers, namely temperature and rain levels and the avian biodiversity in a Mediterranean like Natura 2000 wetland. Birds are the most conspicuous and significant component of freshwater wetland ecosystems [12]. To date, no detailed study has been conducted in a Natura 2000 wetland in Northern Greece to determine the particular association of birds with microclimate variables.

Due to occurrence of both dry summers and mild winters we can expect remarkable variation in bird biodiversity caused by annual fluctuations of climatic conditions. Thus, climatic conditions in Northern Greece offer good opportunity to explore the effects of the above environmental drivers on bird species biodiversity and to highlight possible implications for conservation management. The detection of changes in avian biodiversity may indicate the ecological conditions of the wetland area.

\section{Material and Methods}

\subsection{Study Site}

The current study is performed in the wetland complex of the Thermaikos gulf Natura 2000 protected area in Northern Greece and particularly in the Axios Delta National Park - Loudia - Aliakmonas, with an area of 338 sq.km., which includes the deltas and estuaries of the four rivers, the lagoon of Kalochori and Aliki Kitros, the wetland of Nea Agathoupoli and the riverbed of Axios to and Ellis. The wetland, which is the core of the protected area, is surrounded by irrigated and non-irrigated crops, mainly cereals, and meadows, while in the area there are also small grasslands along with mosaic of lotic and lentic water systems having complex ecosystem of seasonally flooded grassland and pastures. The protected area has high biodiversity and in there have been recorded 297 species of birds, $66 \%$ of the species observed to date in Greece, of which 106 nesting, 350 
species and subspecies of plants, 40 species of mammals, 18 species of reptiles 9 species of amphibians in 25 habitats, two of which are priority habitats at European level [13].

\subsection{Data}

Weather data were obtained by the national observatory of Athens. The climate data included mean temperatures $\left({ }^{\circ} \mathrm{C}\right)$ and relative humidity $(\%)$. Bird data were obtained through the official website of the Thermaikos gulf protected areas management authority. Particularly, the most complete and representative bird watching data sets from 2012 till 2017 of the spatial protection zone (GR1220010) of the Natura 2000 natural park was used for the analysis. All data are published and free accessible and are intellectual property Thermaikos gulf protected areas management authority (Theramaikos gulf protected areas management authority 2020, http://axiosdelta.gr/en/) and have been used after official permission ((license permission: Chalastra 19/3/2019, protocol number: 262).

\subsection{Biodiversity Indexes and Analysis}

Three biodiversity indexes were estimated based on the bird counts recorded including the Shannon diversity, Simspons dominance index and the Berger - Parker index [11]. The Shannon diversity function, is a measure of the information necessary to specify an assemblage and probably the most common biodiversity measure. For only one type in the data set, Shannon entropy equals zero. Therefore, high Shannon entropy stands for high, low Shannon entropy for low diversity. The Simpson's diversity index, [14],is a simple mathematical measure that characterizes the species diversity in a community and the Berger - Parker index, (referred as species dominance in Berger and Parker [15]) is the maximum proportion of any species in a sample. If the community (sample) is dominated by the most common species and it is not even then the Berger-Parker index should be high.

To detect the interrelationship between the two environmental drivers, namely temperature and relative humidity and the different biodiversity indexes, we have fitted on the data a 3D non-linear regression model of the form $f(x, y)=y 0+a^{*} x+b^{*} y+c^{*} x^{2 \wedge} 2+d^{*} y^{2}$, where, $a, b, c$ and $d$ are constant parameters and $x, y$ the dependent environmental variables. Additionally, non-parametric smoothed contour plots where also generated for comparative reasons. The analysis was performed using SigmaPlot version 14.1 from Systat Software, Inc., San Jose California USA, www.systatsoftware.com.

\section{Results}

Non-linear regression modeling provides a surface-plot analysis methodology to link the interrelationship between temperature, relative humidity and the three biodiversity indexes that were tested. The results of the non-linear regression model depicted in Figures $1 \mathrm{a}, 2 \mathrm{a}$ and $3 \mathrm{a}$, while table 1 summarizes the parameter estimated of the non-linear regression model as well as the basic model performance statistics for each case. 


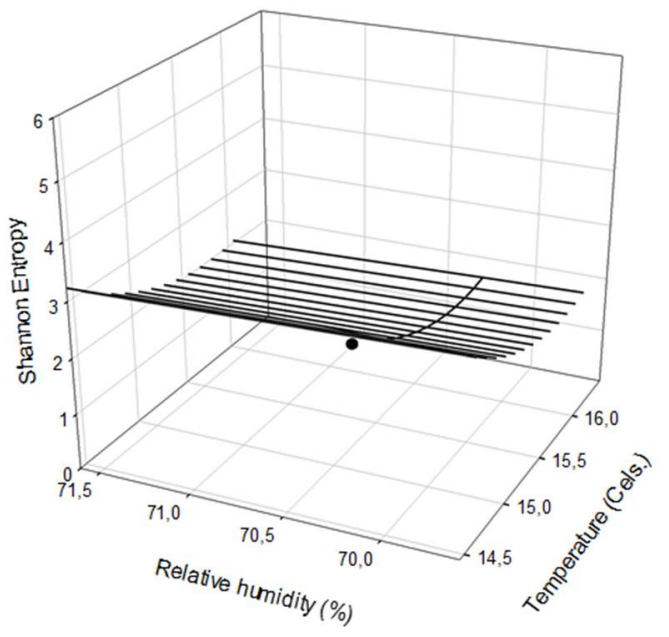

(a)

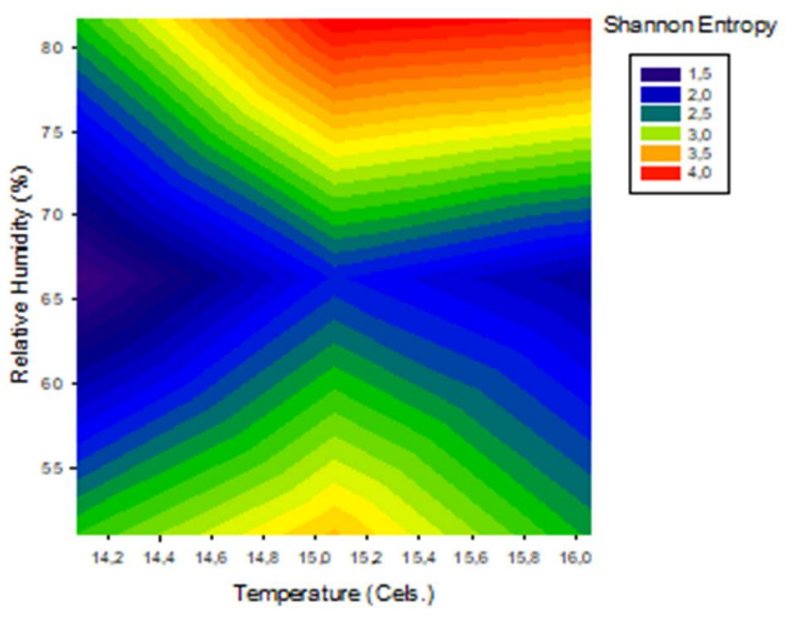

(b)

Figure 1. Interrelationship between annual mean temperature, relative humidity and avian biodiversity expressed as Shannon Entropy according to the (a) non-linear regression model; and the (b) non-parametric counter plots. The dot represents the local minimum (see text for details).

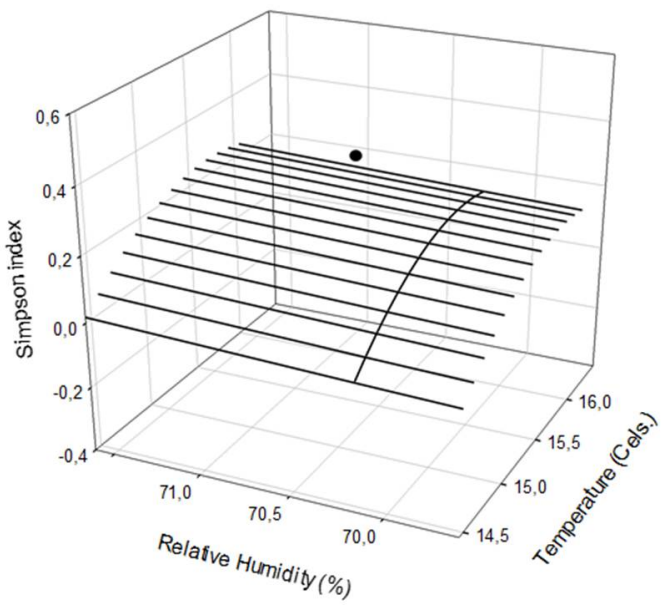

(a)

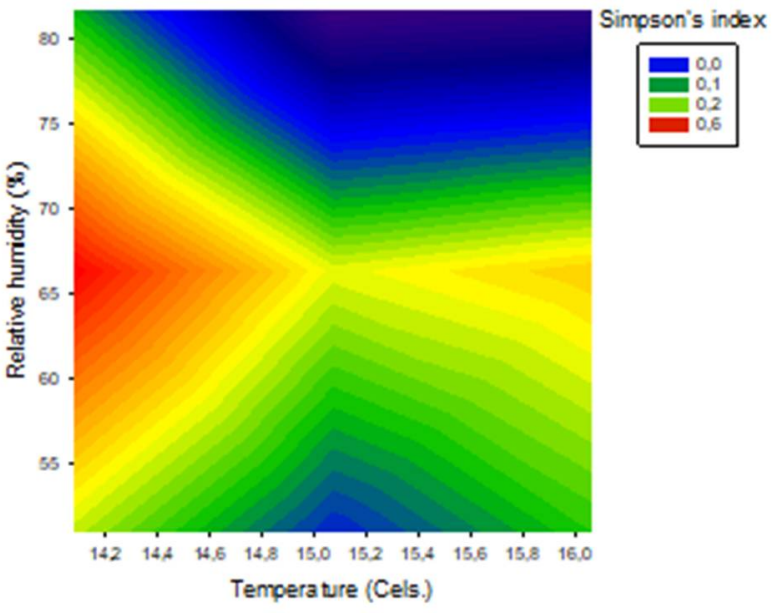

(b)

Figure 2. Interrelationship between annual mean temperature, relative humidity and avian biodiversity expressed as Simpson's index according to the (a) non-linear regression model; and the (b) non-parametric counter plots. The dot represents the local maximum (see text for details).

However, the non-linear models performed less well and accounted close to $50 \%$ of the data variability (Figure $1 \mathrm{a}, 2 \mathrm{~b}$ and $3 \mathrm{c}$ ). This was expected to some extend considering that the data range was relatively small (e.g., 2012-2017). Nevertheless, based on the nonlinear model results the lowest avian biodiversity was, 1.5 according to the Shannon index and was observed at the intermedium temperature and relative humidity levels (e.g., local minimum at $15.4^{\circ} \mathrm{C}$ and $70,6 \% \mathrm{RH}$ ). The Simpson and Berger-Parker diversity indexes showed analogous trend with that of Shannon although on an opposite way. Particularly, the local maximum for the Simpson index 0.58 and for the Berger - Parker 0.28 at $15.4^{\circ} \mathrm{C}$ and $70,6 \% \mathrm{RH}$, respectively. 


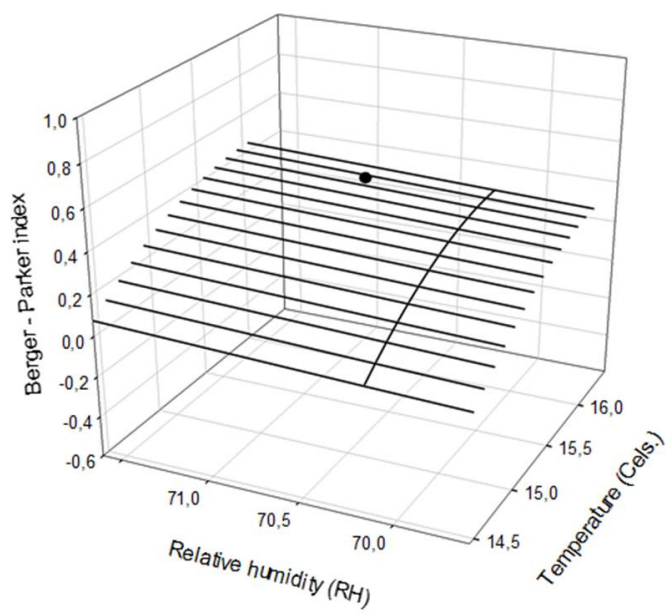

(a)

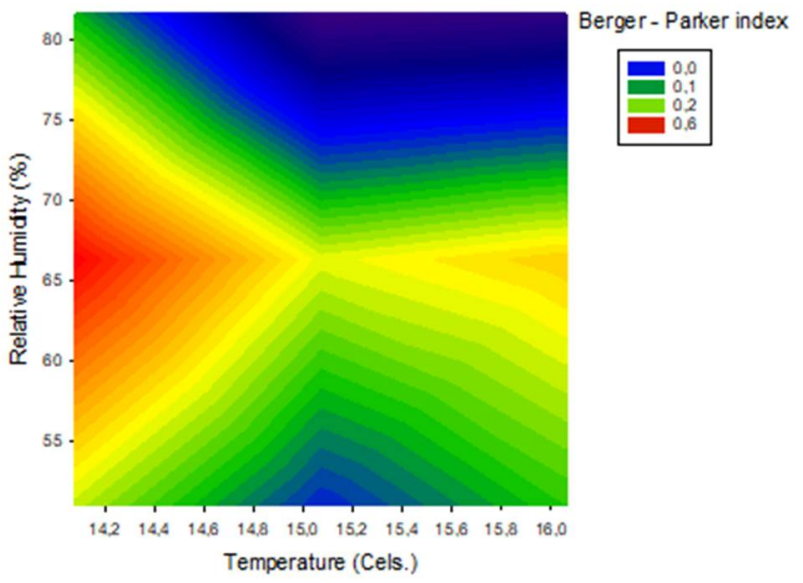

(b)

Figure 3. Interrelationship between annual mean temperature, relative humidity and avian biodiversity expressed as Berger - Parker index according to the (a) non-linear regression model; and the (b) non-parametric counter plots. The dot represents the local maximum (see text for details).

Table 1. Parameter estimates $(y 0, a, b, c)$ of the non-linear regression model ${ }^{1}$ and related statistic performance $\left(R\right.$ and $\left.\mathrm{R}^{2}\right)$.

\begin{tabular}{cccc}
\hline & Shannon & Simpson & Berger-Parker \\
\hline $\mathrm{y} 0$ & 169,004 & $-33,946$ & $-33,453$ \\
$\mathrm{a}$ & $-22,124$ & 4,503 & 4,437 \\
$\mathrm{~b}$ & 0,313 & $-0,079$ & $-0,052$ \\
$\mathrm{c}$ & 0,701 & 0,0008 & $-0,141$ \\
\hline$R$ & 0,67 & 0,657 & 0,584 \\
\hline$R^{2}$ & 0,448 & 0,431 & 0,341 \\
\hline
\end{tabular}

${ }^{1}$ Model is: $f(x, y)=y 0+a^{*} x+b^{*} y+c^{*} x^{2 \wedge} 2+d^{*} y^{2}$

The same trends were also observed by observing the contour plots which depict the biodiversity index as response variable related to the two environmental predictor variables (Figure 5, 6, and 7). The hot colors (e.g., orange to red) indicate higher avian biodiversity as a response to temperature and relative humidity. In particular, the highest biodiversity is observed in the right of graph indicating that for intermediate relative humidity levels and modest to lower temperature levels. Moreover, more contours with cold colors (e.g., blue) are located in the upper and lower part of chart suggesting that the combinations of high humidity (e.g., close to $80 \% \mathrm{RH}$ ) and temperature levels does not favor high biodiversity levels. A similar pattern, although at lower levels, is observed at very low to dry relative humidity levels (e.g., close to $50 \% \mathrm{RH}$ ) and intermediate annual temperatures.

\section{Discussion}

Detecting the association of avian biodiversity with microclimate variables is particularly important to understand the importance, productivity and suitability of a particular area and how these factors affect bird habitat selection and distribution [12]. Climate change has a multifaceted effect on biodiversity which is almost always negative for species. Changes in ambient temperatures, the amount of precipitation (rain, snow, etc.), relative humidity and increasingly frequent extreme weather events are characteristic elements of climate change that directly affect biodiversity [7,17]. 
Climate variables may affect avian survival rate, reproduction success, time of breeding, species dispersion and habitat selection $[16,18,19]$. Climate change is also being assessed that it will exacerbate the loss of species, in particular species of limited range climate and ecological requirements and limited migration possibilities (IPCC 2007) [20]. Moreover, alterations in climate may also affect biodiversity in an indirect way, changing ecosystems and habitat characteristics in an accelerating way and thus modifying the behavior, distribution range and population dynamics of avian assemblages [21]. To the best of our knowledge no detailed study has been conducted in wetland area of Northern Greece to determine the particular association of avian biodiversity with microclimate.

Empirical studies of the relationships between bird population abundance and climatic conditions are not very common $[8,22]$ and most of the current knowledge is based on few studies performed on species level in local scale (e.g. [9, 23]). Based on the nonlinear regression model results and the related contour surface plots we conclude that an increased biodiversity is favored by intermediate levels of relative humidity and temperature. This phenomenon is in accordance with other studies $[24,25]$ and can theoretically be explained due to the direct and/or indirect effects of climatic factors on bird populations and the suitability of their habitats.

Yet it should be noted that most regression models displayed moderate to low coefficient of determination a trend which could be explained by the fact that we have used annual mean (e.g., pooled data for each year of observation) rather than monthly data means and thus the points for the regressions were limited. Nevertheless, the results are informative and especially those derived from the countor plots, since they have been derived using long-term and successive avian biodiversity monitoring data.

It is known, for instance that many bird populations are very sensitive to dry conditions. Furthermore, it is expected that drought conditions will modify wetlands and their composition, while the Mediterranean ecosystems are among the most vulnerable in Europe due to climate alterations as they are close to their environmental boundaries [26]. Bird habitats are expected to be strongly affected by phenomena such as rising sea levels, large fires, changing flora and changing land uses. For example, the Mediterranean coastal wetlands, which are critical for bird migration, will have undergone major changes by 2080, when temperatures are expected to rise from $1.5^{\circ} \mathrm{C}$ to $4.2^{\circ} \mathrm{C}[2,27]$.

Birds, particularly, being very sensitive to weather conditions, are one of the best indicators for monitoring changes that are expected to occur in the future [28]. Climate change already has a distinct negative impact, mostly through influences mediated by vegetation and wetland composition, on bird populations, at European level and threaten their populations. Specifically, according to the European Climate Impact Index, more than $2 / 3$ of bird species are adversely affected by Climate Change $[5,26]$. In this context, the present work can contribute to understanding how climatic factors can affect avian biodiversity. To date the areas most affected by climate change could be the south part of the Iberian Peninsula, the east coast of the Adriatic, and southern Greece [29]. As a result, some wetlands may not be suitable to accommodate a large number of birds because they may not have enough water.

In a broadest context a potential loss in biodiversity implies a degradation of the services provided by ecosystems and particularly semi natural ecosystems such as the Natura 2000 sites. Between ecosystem that could be affected due to the loss of biodiversity include the production of food, fuel, fiber and regulation of water, air and climate, the maintenance of soil fertility and nutrient cycle $[2,30]$. Therefore, in a holistic perspective the preservation of biodiversity and detection of factors affecting it is vital to our health and well-being since it improves quality and enhances living standards, contributes to social prosperity and cohesion and offers new opportunities for investment and work. At the same time, much of this growth has been accompanied by the deterioration of biodiversity. Therefore, biodiversity loss is a cause for concern, not just because of its inherent value, but also because biodiversity is an element of the background on which it is based 
competitiveness, growth and employment, as well as the improvement of living conditions (European Commission 2021) [31].

\section{Conclusions}

The bird biodiversity has been known to play an important role as biodiversity indicator in the wellbeing and health of ecosystems. In the present work, the interrelationship between temperature, relative humidity and avian biodiversity was studied for the first time in a representative natura 2000 wetland in Northern Greece. We detected a considerable interrelationship between annual mean temperatures and relative humidity, with the different avian biodiversity indexes. In particular, we observe an increase in biodiversity for the intermediate levels of relative humidity and temperature, while an opposite trend occurs when the relative humidity and temperature values are in the extreme values. However, there are cases in which the coefficient of determination of the non-linear models were low and this is probably related to fact that we have used for the analysis mean yearly values of temperature and relative humidity along with the biodiversity values for a limited number of years (e.g., 2012-2017). Yet, this study has shown that avian biodiversity is considerably affected by differentiations of the annual values of the environmental variables and thus may contribute to our understanding on how climate change may affect biodiversity. These findings are expected to improve our understanding of the effects of microclimate on avian biodiversity and improve conservation management in the particular area of research.

Author Contributions: "P.S. conceived and designed the study; P.S. analyzed the data and wrote the paper; P.D. contributed in analysis tools; M.A.P.D, J.A.M.M and P.D. reviewed, revised and edited the article.

Conflicts of Interest: "The authors declare no conflict of interest."

\section{References}

1. Legakis,A; Constantinidis, T.; and Panos V. Petrakis. P.V., 2019. Biodiversity of Greece. Chapter 2. In Global Biodiversity, Volume 2, Selected Countries in Europe. Editor T. Pullaiah, Apple Academic Press.

2. Vella, E.; Kyriakopoulou, E., Xepapadeas, A., 2011. Risks and Impacts of Climate Change on Biodiversity in Ecosystems. Report of Climate Change Impacts Study commetee. Eds. National Bank of Greece. Eurosystem.(In Greek).

3. EEA, 2005. "Vulnerability and Adaptation to Climate Change in Europe", EEA Technical Report No 7/2005, European Environment Agency, Copenhagen.

4. Beniston, M.; Stephenson D.B.; Christensen O.B.; Ferro, C.A.T. et al., 2007. Future extreme events in European climate: an exploration of regional climate model projections. Climatic Change, 81, 71-95.

5. ESA, 2021. The European agency. Available online: http://www.esa.int/Applications/Observing the Earth/Securing Our Environment/Biodiversity habitats (accessed on 18/2/2021).

6. Tucker G.M. \& Evans M.I., 1997. Habitats for Birds in Europe: a Conservation Strategy for the Wider Environment. Cambridge: BirdLife International.

7. Chen, K.L., 1998. Wetlands and waterbirds of China. Bull Biol.,33, 2-4.

8. Jones, J.; Doran, P.J.; Holmes, R.T. 2003. Climate and food synchronize regional forest bird. Ecology, 84, $3024-3032$.

9. Virkkala R., 2004. Bird species dynamics in a managed southern boreal forest in Finland. Forest Ecol. Manag. 195: 151-163.

10. Chrysopolitou Vasiliki and Helena Hadjicharalambous (editors). 2008. Second National Report on the Implementation of the Habitats Directive in Greece (reporting period 2001-2006): Factsheets and maps of the habitat types (Annex I) and species (Annexes II, IV and V) that occur in Greece. Hellenic Ministry for the Environment, Physical Planning and Public Works, Athens and Greek Biotope / Wetland Centre (EKBY). Thermi, Greece.

11. Soulopoulou P.; Molina J.A.M.; Padilla-Blanco, M.A.; Damos P., 2020. Temporal variation of bird biodiversity and compositional complexity in a representative semi-Agricultural Natura 2000 area of conservation in Northern Greece. Biodiversity Journal, 11: 939-950.

12. Rajpar, M.N.; Zakaria, M., 2015. Bird abundance and its relationship with microclimate and habitat variables in open-area and shrub habitats in selangor paninsula Malaysia. J. Anim. Plant Sciences, 25, 2015, Page:114-124ISSN: 1018-708. 
13. Vokou D., Giannakou U., Kontaxi C., Vareltzidou S., 2018. Axios, Aliakmon \& Gallikos Delta Complex (Northern Greece). In: Finlayson C., Milton G., Pren-tice R. \& Davidson N. (Eds.), The Wetland Book. Springer, Dordrecht, pp. $1137-1147$.

14. Simpson, E.H. 1949. Measurement of diversity. Nature 163, 688.cited in Magurran, A. E., 2004. Measuring biological diversity, Blackwell Publishing: Oxford, UK.256 p, 1949.

15. Berger, W.H., Parker, F.L., 1970. Diversity of planktonic foraminifera in deep-sea sediments. Science, 168: 1345-134.

16. Rajpar, M.N.; Zakaria M., 2011. Bird species abundance and their correlationship with microclimate and habitat variables at natural wetland reserve, Peninsular Malaysia. Int. J.Zoology, Article ID 758573, 17pages. DOI:10.1155/2011/758573

17. Wang XD, Kuang FL, Tan K, Ma ZJ. Population trends, threats, and conservation recommendations for waterbirds in China. Avian Res. 2018; 9:14.

18. Zharikov,Y.; Skilleter, G.A. 2002. Sex-specific intertidal habitat use in sub-tropically wintering Bar-tailed Godwits. Canad. J. Zoology, 80, 1918-1929.

19. Norvell, R.E.; Howe, F.P.; Parrish, J.R. 2003. A seven-year comparison of relative-abundance and distance sampling methods. Auk, 120, 1014-1028.

20. IPCC, Intergovernmental panel of climate change. Climate change and Biodiversity, IPCC Technical Paper V. Available on line: https://archive.ipcc.ch/pdf/technical-papers/climate-changes-biodiversity-en.pdf (accessed 19/2/2021).

21. Duclos, T. R.; DeLuca, W. V.; King, D. I; 2017. Direct and indirect effects of climate on bird abundance along elevation gradients in the Northern Appalachian mountain. Biodiversity Research. DOI: 10.1111/ddi.12968.

22. Reif, J.; Telenský, T.; Št’astný, K.; Bejček, V. et al., 2010 Relationships between winter temperature and breeding bird abundance on community level: importance of interspecific differences in diet. Folia Zool., 59, 313-322.

23. Holmes, R.T.; Sherry, T. W.; Sturges F.W. 1986. Bird community dynamics in a temperate deciduous Forest: Long-term trends at Hubbard Brook. Ecol Mon., 56, 201.

24. Williams, S.E.; Middleton, J; 2008. Climatic seasonality, resource bottlenecks, and abundance of rainforest birds: implications for global climate change. Diversity and Distributions, 14, 69-77.

25. Herrando, S.; Titeux, N.; Brotons, L. et al. 2019. Contrasting impacts of precipitation on Mediterranean birds and butterflies. Sci Rep 9, 5680. https://doi.org/10.1038/s41598-019-42171-4

26. European Environment Agency (EEA), 2010. "10 messages for 2010. Climate Change and Biodiversity”, Copenhagen.

27. Berry, P.M.; Jones A.P.; Nicholls, R.J.; Vos C.C. (eds.), 2007. "Assessment of the vulnerability of terrestrial and coastal habitats and species in Europe to climate change, Annex 2 of Planning for biodiversity in a changing climate - BRANCH project Final Report", Natural England, UK.

28. Sæther, B.E.; Tufto, J.; Engen, S.; Jerstad, K.; Rostad, O.W.; Skatan J.E., 2000. Population dynamical consequences of climate change for a small temperate songbird. Science, 287, 854-856.

29. Beniston, M.; Stephenson, D.B; Christensen, O.B. et al., 2007. Future extreme events in European climate: an exploration of regional climate model projections. Climatic Change, 81, S71-S95.

30. Schröter, D., Cramer, W., Leemans, et al. (2005), "Ecosystem Service Supply and Vulnerability to Global Change in Europe", Science, 310, 1333-1337.

31. European Commision 2012. Biodiversity strategy for 2030 - concrete actions. Available on: https://ec.europa.eu/environment/strategy/biodiversity-strategy-2030_en (accessed: 18/2/2021) 